\title{
Desde el republicanismo clásico hasta el contractualismo moderno: el De Principatu de M. Salamone y el Principatus Politicus de F. Suárez
}

\author{
Maria Antonietta SALAMONE SAVONA \\ UCM \\ (salamonema@filos.ucm.es)
}

\section{RESUMEN}

A la doctrina del "absolutismo regio" formulada por N. Maquiavelo en El Príncipe, y luego apoyada por las Reforma Protestante, se contrapuso en el siglo XVI (1513) la doctrina republicana del "contrato social" celebrada por Mario Salamone en El Principado. Esta doctrina fue luego respaldada por los jesuitas españoles, como F. Suárez, y los calvinistas franceses o alemanes, como J. Althusius, que defenderán el principio de la Soberanía popular, es decir el origen ético-jurídico del poder político, o el estado de derecho, frente a la Teocracia

PALABRAS CLAVES: republicanismo; contractualismo; Mario Salamone; Francisco Suárez.

\begin{abstract}
In the sixteenth century (1513), the doctrine of "royal absolutism", proposed by N. Machiavelli in The Prince and then supported by the Protestant Reformation, was contrasted by the Republican doctrine of "social contract", formulated by M. Salamone in The Principality. This doctrine was further supported by the Spanish Jesuits as F. Suárez, and the French or German Calvinists as J. Althusius, whose will defend the principle of popular sovereignty, that is to say the ethical-legal foundation of political power, or the rule of law, against Theocracy
\end{abstract}

KEY WORDS: republicanism; contractualism; Mario Salamone; Francisco Suárez.

\section{Desde el Republicanismo clásico hasta el Contractualismo de Mario Salamone}

La idea del origen convencional del poder político nace con los Sofistas: para ellos la constitución del Estado expresa solamente los intereses de los que mandan, de los gobernantes, es decir lo útil para los más fuertes; los Sofistas, en efecto, distinguen entre la "multiplicidad" del derecho positivo que expresa los intereses de los gobernantes (constituciones tiránicas, oligárquicas y democráticas), y la "unidad" del derecho natural que se basa en el principio ético de que todos los hombres son libres e iguales por naturaleza. Ha sido mérito de Platón y de Aristóteles superar esta dicotomía o división entre el derecho positivo y el derecho natural (y alcanzar, por consiguiente, la unidad en la multiplicidad), al demostrar que el fin de la política es la justicia, es decir lo útil para los gobernados y que, por lo tanto, el fundamento del poder político es ético antes de ser jurídico. Aristóteles, además, consiguió determinar científicamente que la mejor constitución política es la República 
Aristocrática ${ }^{1}$, es decir la constitución mixta, en la cual los derechos y deberes tanto políticos como económicos se reparten de forma equitativa entre las diferentes clases sociales para el bien de toda la ciudad. Después de los griegos, los romanos desarrollaron los medios más idóneos para realizar el ideal de la constitución mixta señalada por Aristóteles, es decir el derecho romano. Para Cicerón ${ }^{2}$, en efecto, la república es lo que pertenece al pueblo; pero pueblo no es todo conjunto de hombres reunidos de cualquier manera, sino que los hombres se han reunido en una sociedad por el acuerdo sobre la justicia (consensus iuris) y la comunión de intereses (communio utilitas). Según Cicerón, pues, la república se identifica con el acuerdo sobre la justicia y la comunión de intereses; en cuanto este vínculo se rompa, se acaba también la razón de ser de la república; además, la masa se convierte en pueblo sólo a través del derecho, a través de la ley o la constitución. El Estado ético de los griegos, por lo tanto, se hace jurídico, se define en una forma de gobierno, una constitución y un ordenamiento jurídico. Así pues, ya el mundo clásico había logrado fijar los pilares fundamentales en torno a los cuales había de desarrollarse la doctrina del contractualismo, es decir el fundamento éticojurídico del poder político.

Durante el Medioevo cristiano, los Padres de la Iglesia y la Escolástica profundizaron esta concepción de la política, destacando el principio de la libertad e igualdad de todos los hombres en cuanto hijos de Dios y el interés por distinguir la ley natural-divina establecida por Dios (las Tablas de Moisés: la ciudad de Dios) de la ley positiva-humana establecida por el hombre (la Ley de las XII Tablas: la ciudad Terrena), lo cual les permitió separar las competencias de los dos ámbitos: lo espiritual y lo político. Para el cristianismo el individuo es un sujeto moral y metafísico dotado de absoluta igualdad y libertad, así que cuando el Estado pretende imponer algo que atañe a la vida espiritual del individuo, se rompe el vínculo con el Estado: el poder se convierte en ilegítimo por salirse de las normas establecidas en el consensus iuris y el cristiano, por consiguiente, no tiene la obligación de obedecer al poder constituido. Fue San Agustín quien expresó claramente esta contraposición entre el derecho natural-divino y el derecho positivo-humano, que justifica el derecho de resistencia a la autoridad injusta; esta aclaración agustiniana representa, por consiguiente, una de las etapas fundamentales del desarrollo de la idea contractual en cuanto explica el papel concreto del derecho natural o de

\footnotetext{
1 M. A. SALAMONE, La Ética y la Politica de Aristóteles: una cuestión de proporciones áureas, Milán, Lampi di Stampa, 2007.

2 CICERÓN, Sobre la República. Sobre las Leyes, Madrid, Tecnos, 2000.
} 
lo moral, que tiene que orientar las normas del derecho positivo y vigilar, por lo tanto, la legitimidad o falta de la misma del poder político. Tomás de Aquino, por su parte, tras haber precisado que el poder político para ser legítimo tiene que expresarse únicamente en el ámbito del derecho y fundamentarse, por tanto, en el acuerdo sobre la justicia, llegó a definir el principio sobre la base del cual hay que decidir si el poder político es legítimo, constitucional o no; en efecto, según Tomás de Aquino, quien toma el poder con el engaño y con la violencia no es un rey sino un tirano porque su poder no procede de la voluntad de los súbditos: el Estado, por lo tanto, es ilegal cuando se pone en contra de la justicia y del derecho natural a la libertad e igualdad de los hombres.

Luego, este principio tomista fue asumido y reelaborado por la Escuela Jurídica Italiana (Roma y Bolonia) que consiguió avanzar en el proceso de racionalización del poder político llegando a teorizar el concepto de soberanía popular (Marsilio de Padua en Defensor Pacis); establecer que el criterio para determinar si hay tiranía o no reside, en última instancia, en el ordenamiento jurídico adoptado por la Universitas civium (Bartolo de Sassoferrato en De Tyrannia); precisar que el pueblo tiene el derecho de revocar y deponer a quien se apodera ilegítimamente del poder político (Coluccio Salutati en De Tyranno); concretar, por lo tanto, la idea jurídico-política de "pacto de gobierno" entre el pueblo y el rey (Nicolás de Cusa en De concordantia Catholica); hasta clasificar los derechos fundamentales o constitucionales de los ciudadanos que no deben ser quebrantados por quien asume el poder político del Estado (Paride del Pozzo en Tractatus de sindacatu). De tal manera que toda la temática contractual quedó incorporada al ámbito de la jurisprudencia. A partir de este momento, algunos autores intentaron identificar exactamente qué clase de vínculos jurídicos, de acuerdos y de pactos tendrían que establecer los individuos para fundar una sociedad y un Estado legítimo y evitar, por lo tanto, toda clase de tiranía. Una de las fuentes principales del principio de la soberanía popular y de la doctrina del "contractualismo" fue si duda alguna el derecho romano. En efecto, la autoridad del Digesto -invocada durante la edad media por gobernantes con aspiraciones absolutistas, tiránicas y teocráticas para legitimar el propio dominio sobre los súbditos, gracias a la máxima de que todo príncipe debe ser visto como legibus solutus, es decir libre de la obligación de la ley- se convirtió, a comienzo del siglo XVI, en el mejor apoyo de la causa democrática y constitucionalista. En esa época, en efecto, humanistas jurídicos de la talla de Ulrico Zasio, Andrea Alciato y Antonio de Nebrija, empezaron a tomar un nuevo interés por la historia del derecho romano al investigar, por primera vez, las circunstancias 
exactas en que originalmente el Senado y el Pueblo romano otorgaron -a través de la Lex Regia- la concesión del Imperium al emperador Augusto al comienzo del Principado. El más destacado jurisconsulto que se valió de las técnicas humanistas para fijar una teoría esencialmente democrática de la soberanía popular e interpretar la concesión de la soberanía encarnada en la Lex Regia en un sentido constitucionalista -provocando una auténtica revolución copernicana en el campo de las ciencias políticas- fue Mario Salamone ${ }^{3}$. Máximo exponente de la Escuela jurídica italiana, Salamone ocupó cargos políticos de gran relevancia en la república de Florencia, en el común de Roma y en la Curia vaticana. En Roma fue nombrado varias veces Gobernador (la máxima magistratura de la Cámara capitolina), Diputado de la región Campitelli (es decir representante del Senado romano) y Profesor de derecho civil por la Universidad La Sapienza; en la Curia vaticana fue nombrado Conde palatino y Abogado del Sacro consistorio; mientras que en Florencia fue nombrado Capitán del pueblo -la más antigua e importante magistratura de la república (1265), es decir señor de toda Toscana, defensor de las artes y de la libertad del pueblo, guardián de la paz y tranquilidad del territorio -desde el 21 de octubre de 1498 hasta el 20 de abril de 1499, o sea unos meses después de la muerte del Savonarola y tras la expulsión de los Médicis de la ciudad. En efecto, Salamone fue uno de los padres fundadores no sólo de la célebre constitución republicana florentina del 23 de Diciembre de 1494, sino que principalmente fue el grande artífice de la reforma republicana de los Estatutos romanos, publicada entre el 1519 y el 1523, ya que promovió, bien política bien jurídicamente, la puesta en marcha de gobiernos republicanos fundamentados en la igualdad y libertad de los ciudadanos. En Florencia, por ejemplo, bajo su capitaneado se aprobaron la importantísima reforma fiscal de la Decima Scalata-que introdujo el «impuesto sobre la propiedad» del 10\% por primera vez en la historia no solamente de Florencia sino de toda Italia- y la reforma electoral que permitió a la clase media florentina incorporarse finalmente en el gobierno de la república.

Precursor católico de algunos conceptos políticos considerados propios del ambiente calvinista y reformista, Salamone provenía de Sicilia, como atestigua unos de sus contemporáneos que más lo estimó, el jurista Antonio Vacca, debiéndolo presentar al gran humanista Jacobo Corbinelli para que publicase la edición parisina de El Principado ${ }^{4}$. En su

3 M. D’ADDIO, L'idea del contratto sociale dai sofisti alla riforma e il De Pricipatu di Mario Salamone, Milano, Giuffré, 1954.

${ }^{4}$ M. SALAMONII, De Principatu, Roma, manuscrito Biblioteca Vaticana, 1513. 
obra principal, en efecto, Salamone ofrece una demostración tajante del fundamento éticojurídico del poder político y del carácter contractual de la ley, al interpretar histórica y jurídicamente las instituciones del Principado romano y sobre todo la célebre Lex Regia, que se convierte a partir de entonces -y durante los siglos XVI y XVII- en el primer paradigma filosófico del contractualismo moderno. El Príncipe romano - demuestra Mario Salamoneno fue nunca legibus solutus sino un ministro del pueblo, encargado de gobernar la república bajo los dictámenes de la Lex Regia promulgada por el pueblo. En pocas palabras, el autor demolió el falso presupuesto histórico sobre el cual se había cimentado anteriormente todo tipo de absolutismo regio, o sea la supuesta norma del Digesto del Príncipe legibus solutus que había sido utilizada durante la baja edad media para justificar todo tipo de tiranía. Y con el fin de la teoría clásica del Princeps legibus solutus se dio comienzo al pensamiento político moderno, cuya problemática fundamental será la de poner límites precisos al absolutismo del Príncipe, de constitucionalizar el poder político, o sea de considerar el Príncipe como un magistrado del pueblo y no como un verdadero soberano. De tal manera que todos los temas desarrollados en los siete libros que componen El Principado -la soberanía popular, el pacto social, el pacto de gobierno y el derecho de resistencia,-- hacen de la concepción política de Salamone la primera teoría republicana y contractualista de la época moderna. Además, esta doctrina política se opone radicalmente al pensamiento político del contemporáneo N. Maquiavelo, al afirmar la estrecha conexión entre el derecho positivo y el derecho natural. El problema fundamental de Salamone, en efecto, es el de determinar el fundamento ético-jurídico de la sociedad política frente a la doctrina maquiavélica según la cual el poder político es libre de la obligación tanto de la ética como de la ley. En El Principado, un diálogo platónico entre un jurista, un filósofo, un historiador y un teólogo, Salamone ${ }^{5}$ en efecto, sentó las bases del contractualismo moderno al contestar a cuatro preguntas fundamentales que constituyen los cuatros pilares de la nueva doctrina política:

1) ¿En la comunidad política hay una potestas que está por encima del Príncipe?

\footnotetext{
${ }^{5}$ M. A. SALAMONE, La idea del contrato social en Mario Salamone de Alberteschi: sus vínculos con la Escuela de Salamanca y el Constitucionalismo inglés, Madrid, Servicio de Publicaciones de la Universidad Complutense, 2006.
} 
La respuesta se desarrolla a través de los "argumentos de la autoridad del Papado", de la "causa eficiente", de las "magistraturas" y de las "propiedades del Principado". Todos los hombres, afirma el autor, son libres e iguales por derecho natural y, por lo tanto, por encima del poder político del Príncipe se encuentra la Soberanía del pueblo. El pueblo, en efecto, instituyó los principados por su propia voluntad y, como ningún individuo se esclaviza voluntariamente, del mismo modo el pueblo no instituyó al Príncipe para que este se convirtiera en su amo. De tal manera que por encima del Príncipe no hay otro magistrado que el Pueblo entero; todas las leyes promulgadas por el Príncipe tienen la vim coactivam porque hay que considerarlas como manifestación de la soberanía popular. En efecto, las leyes proceden sólo formalmente del Príncipe puesto que en realidad son manifestaciones de la autoritas y del imperium popular. Además es por eso que tras la muerte del Príncipe las leyes siguen teniendo validez: si las leyes se fundamentan en el pueblo, entonces participan de la vida eterna del pueblo y no se limitan ni vinculan su existencia a la del Príncipe.

2) ¿El poder del Príncipe para promulgar las leyes se justifica por sí mismo o más bien depende de una autoridad externa?

La respuesta se desarrolla a través del importantísimo "argumento del mandante y del mandatario", es decir a través del principio del contrato de mandato tomado del derecho civil. El poder del Príncipe, demuestra Salamone, no se justifica por sí mismo sino que depende del Pacto o mandato de Gobierno que establece que el Príncipe es sólo un mandatario o ministro del pueblo. El Príncipe que toma posesión del gobierno bajo el mandato del pueblo se configura, según la argumentación, propiamente como un auténtico mandatario, es decir como una persona encargada de cumplir determinados actos por cuenta del pueblo. El mandato de gobierno, en efecto, es el pacto que une el Príncipe con el Pueblo y se fundamenta en los siguientes principios: a) el Príncipe, o el mandatario, representa el pueblo que es su mandante; b) la acción política del Príncipe y la legitimidad de sus actos tienen valor solamente en el ámbito de su mandato; c) el Príncipe es un minister del pueblo y, por consiguiente, su poder monárquico no es absoluto sino limitado.

3) ¿Existen leyes que posean una autoridad mayor que la del Príncipe?

La respuesta se desarrolla a través del "argumento de la Lex Regia", la definición del Estado y la definición de Ley. Según el autor el Pacto o Contrato Social es la ley que fundamenta y justifica el poder político y se identifica con la constitución; por consiguiente tanto el Pueblo 
como el Príncipe quedan sometidos a la ley constitucional, que marca no solamente los límites sino también el fin del poder político que es la justicia.

4) ¿Puede el Príncipe abrogar leyes arbitrariamente?

La respuesta se encuentra en la definición del poder político del Príncipe: cuando el Príncipe actúa en contra de la justicia, al violar el contrato social se convierte en un tirano y, por consiguiente, el pueblo tiene el derecho a rebelarse e incluso puede llegar al tiranicidio: Derecho de Resistencia. En lugar de ser la encarnación del poder soberano procedente de Dios, y por lo tanto superior al pueblo además que legibus solutus, la autoridad y la potestad del Príncipe quedan definidas, limitadas y legitimadas con referencia a las siguientes y concretas características. El Príncipe es: I) el primero entre iguales en «autoridad» política (prius inter pares); II) inferior al pueblo en «potestad» política (inferior universo populo); III) su libertad de gobierno encuentra un límite jurídico en la ley que define el marco y el fin de la política que es la justicia; IV) un educador y no un amo del pueblo.

Justamente por eso, Salamone ha sido considerado por sus contemporáneos como uno de los humanistas jurídicos más prestigiosos del siglo XVI. Así lo atestiguan Andrea Alciato en sus cartas personales y Andrés Tiraqueau para quien: "Marius Salomonius, vir plane et iuris et humanitatis doctissimus"\%. Para el humanista español Juan Luis Vives el mérito de Salamone ha sido el de comprender la razón política de las instituciones jurídicas a través de un continuo llamamiento a la realidad histórica. En el tercer capítulo del libro VII del tratado enciclopédico De las disciplinas (1531) que lleva el título Cuales deben ser las prendas que conviene que adornen a quien interpreta la justicia, y como ésta los tuvo completamente desnudos de ellas. Donoso apodo que les saca el autor, Vives cita a Mario Salamone al hablar de los requisitos que han de poseer los juristas. En efecto, el filósofo valenciano considera que los juristas necesitan no solamente de conocimientos filológicos, tanto del idioma griego como del latín, sino también de conocimientos arqueológicos e históricos. A este respecto, Budeo, Alciato, Zasio, Salamone y Nebrija son mencionados por Vives como los estudiosos que han contribuido a una comprensión más profunda del derecho con su pericia en estas materias y en contraposición con la mayoría de los juristas de la baja edad media que no fueron capaces de interpretar correctamente ni tan sólo las palabras y expresiones más usuales; lo que explicaría el hecho de que el Corpus iuris civilis estuviera repleto de errores. Según Vives, la función propia del jurista

\footnotetext{
${ }^{6}$ A. TIRAQUEAU, Commentarii in legem si unquam, Lyon, Lugduni, 1547, 308.
} 
no consiste, en efecto, en citar las leyes civiles romanas o sus glosas, sobre todo porque el derecho no se reduce a las leyes romanas y también porque hay que tener en cuenta que las leyes van produciéndose continuamente en relación con la ratio vivendi y el status rerum. La referencia clara e implícita al Principado es muy evidente: "Muchas son las leyes escritas en griego y perversamente traducidas al latín por un interprete idiota, y por esto casi todos los vocablos griegos simples que quedaron incrustados a manera de fósiles en el derecho civil llegaron a nosotros depravados y confusos. A la ignorancia del griego súmase la impericia del idioma latino y de todos aquellos objetos de los que se hace frecuente mención en el derecho civil, como son vestuario, ajuar, aperos de labranza, y de las cosas y costumbres forenses y de toda la ciudad de Roma, en donde está situada la intención de las leyes. Añádase a esto que el olvido aplomó y sepultó la historia y la cronología, y por esta causa, donde leían cielo expositaron cucúrbita e inventaron fábulas, porque ignoraban hechos. De una y otra cosa, adujera yo copiosos ejemplos, si ya no fueran conocidos por todos los que tienen una instrucción mediana, por aquellos libros que escribieron los que arrimaron el hombro a ilustrar la ciencia jurídica, con la ayuda de la filología y de la arqueología: Budeo, Alciato, Zasio, Salamone, Nebrija"7. En el siglo XVI, en efecto, y gracias sobre todo a las iniciativas editoriales francesas llevadas a cabo por Jacobo Corbinelli ${ }^{8}$, la fama de Salamone ya había desbordado las antiguas murallas romanas para conquistar el vasto público europeo. Las mismísimas Vindiciae contra tyrannos, publicadas anónimas y en latín en 1579 y luego en francés en 1581 -y atribuidas posteriormente al hugonote Du Plessis Mornay- se escribieron bajo la influencia de la Escuela Jurídica italiana encabezada por el gran Bartolo de Sassoferrato (a quien se cita expresamente) y el mismo Salamone. Sin embargo, hay que esperar al siglo XVII, para que el máximo representante del movimiento reformista calvinista alemán -Johannes Althusius9- hiciese referencia explicita en su Politica Methodice digesta a Mario Salamone (juntamente con otros autores como Covarrubias, Vázquez y Buchanan) para fundamentar sus ideas del pacto social, del concepto de soberanía popular y del poder del Príncipe como autoridad encargada por el pueblo. Efectivamente, las citas se encuentran principalmente en el capítulo sobre la Comisión del reino o poder universal, donde Althusius desarrolla la teoría del

\footnotetext{
7 J. L. VIVES, Obras Completas, Madrid, Aguilar, 1948, Tomo II, 519.

8 M. SALAMONII, De Principatu, Paris, ed. J. Corbinelli, 1578.

${ }^{9}$ J. ALTHUSIUS, Política Methodice Digesta, atque exemplis sacris et prophanis illustrata, Frankfurt, Klostermann, 1948.
} 
contrato de mandato entre el pueblo y el magistrado, y distingue entre el pactum constitutionis y el pactum subiectionis. Y lo mismo cabe decir de Hugo Grocio ${ }^{10}$ quien escribió su importante tratado sobre el derecho natural para fundamentar el derecho internacional. Por otra parte, no cabe duda de que hubo una grande influencia de Mario Salamone en Francisco De Vitoria11, y, sobre todo, Francisco Suárez ${ }^{12}$ como iremos viendo en el siguiente capítulo. Sin embargo, fue el profesor de la Universidad de Halle, Jacobo Thomasius, quien interpretó abiertamente y por primera vez la doctrina política de Salamone contraponiéndola a la de Maquiavelo. En efecto el autor afirma que se puede elegir políticamente entre dos principios antitéticos: el de Maquievelo que considera que el fin de la política es el interés personal de los gobernantes, y el del monarcómaco católico Salamone según el cual la soberanía descansa en el pueblo y tiene como objetivo alcanzar la justicia o el bien común. Pero fue el hijo de Jacobo, Christian Thomasius $^{13}$, uno de los principales iusnaturalistas del siglo XVII, quien dio por sentado que todo el planteamiento filosófico y jurídico monarcómaco, es decir republicano y antimaquiavélico, había sido puesto en marcha por Marsilio da Padua y Mario Salamone. Así que, aunque la historiografía del siglo XVII haya tenido el mérito de haber colocado correctamente la obra del Salamone, sin embargo no llegó a darse cuenta de las diferencias culturales e ideales que inspiraron al autor italiano con respecto al pensamiento monarcómaco calvinista y, por consiguiente, no logró descubrir lo que había de realmente novedoso en la teoría política del autor italiano. Fueron algunos de los estudiosos más acreditados de la historiografía moderna quienes llegaron a valorar la figura del renacentista italiano, cuya importancia reside fundamentalmente en el hecho de que Salamone introdujo por primera vez en la historia del contrato social el principio de pactum societatis como fundamento de la sociedad civil y del Estado, y eso mucho antes de que lo hiciera el mismo Althusius. En este sentido, el primer historiador que marcó un antes y un después en la historiografía política referente al autor del Principado fue Otto von Gierke que puso bien en claro el hecho de que Mario Salamone fue el primer autor que consiguió fundamentar la soberanía popular sobre el derecho natural interpretando, consecuentemente, el Estado no en sentido organicista (como lo entendía el pensamiento monarcómaco calvinista y el derecho germánico), sino en sentido

${ }^{10}$ H. GROTIUS, De iure belli ac pacis, Madrid, Centro de Estudios Constitucionales, 1987.

11 F. de VITORIA, Relectio de Potestate Civili: estudios sobre su Filosofía Politica, Madrid, Consejo Superior de Investigaciones Científicas, 2008.

${ }^{12}$ F. SUÁREZ, Tratado de las Leyes y de Dios Legislador, Madrid, Instituto de Estudios Políticos, 1967.

13 C. THOMASIUS, Introductio ad philosophiam aulicam, Halle Magdeburgicae, 1702. 
individualista o sea como la unión de los individuos que constituyen la sociedad a través del contrato social (tal como lo entendía el pensamiento monarcòmaco católico ligado a la tradición del Derecho Romano). En el segundo capítulo de la obra titulada Teoría del contrato de Estado, en efecto, Gierke afirma que fue Mario Salamone el que explicó detalladamente el concepto de pacto social como fundamento de la sociedad civil: "Nachdem Salomonius I S.35 ff. jedes Gesetz für einen ausdrücklichen oder stillschweigenden Vertrag (consensus in idem, pactum et stipulatio) erklärt hat, führt er S. 38-42 aus, dass die civitas als civilis societas notwendig bereits voranliegende pactiones und also leges voraussetzt, indem es für jede societas einer vorherigen Übereinkunft, der Festsetzung der Bedingungen und der Erklärung des Willens, sich daran zu binden, bedarf; dass ferner, wie in jeder societas gegen sich selbst, wol aber aller socii unter einender erzeugen; dass endlich auch der Vorsteher der societas und mithin auch im Staat der als prepositus vel institor societatis bestellter Fürst an dieser Gebundenheit Theil nimmt"14. De la misma opinión sería otro importante historiador de la época, J. W. Allen que, además de situar la obra del autor italiano dentro del marco del pensamiento contractual del siglo XVI, subrayó que Mario Salamone fue el primero en plantear la teoría del pactum societatis como acto dependiente exclusivamente de la voluntad de los individuos: "The most original contributions made by the Vindiciae to the theory of sovereignty developed by Huguenot writers after 1572, were, not its suggestion of formal contract, but its suggestion of a federal system based on recognition of the rights of natural communities and its theory as to the nature of law. The first of these, later developed by Althusius, was not followed by the author: it appears almost accidentally. The second was medieval and, in the sixteen century, had been more than anticipated by the writers who called himself Marius Salamonius. In fact substantially, the whole theory of the Huguenot writers may be said with certain qualification, to have been developed and supplemented, partly by Salamonius and partly by Buchanan, before the appears of the Vinciciae. (...) Like the author of the Vindiciae, Salamonius may be said to have formulated a contract theory. But between the two there are two important and radical differences. On the author's own showing the socalled contracts of the Vindiciae are not voluntary agreements. They derive not from the will of the parties but from the will of God and are not therefore, in any accurate sense, contracts

\footnotetext{
${ }^{14}$ O. von GIERKE, J. Althusius und die Entwicklung der naturrechtlichen Staatstheorien, Breslau, M. und Marcus, $1913,98$.
} 
at all. In the De Principatu God is not a party to the contract and this, perhaps, is the most remarkable thing about it. In the second place, the contract of Salamonius in not between Prince and People: the Prince is a mere delegate. He is bound by the contract only as a citizen and as all citizens are bond. The contract is a social contract, not a contract of government. It consists in an understanding among the individual members of any political entity as to the terms of their association. This understating, according to Salamonius, is expressed in the Law of the State. The society that establishes legal sovereignty is conceived as formed by an agreement among individuals which may be termed pactio"15. Mas otro autor muy importante, J. W. Gough se ha ido aún más lejos afirmando tajantemente -al situar correcta y definitivamente el El Principado en su contexto histórico y cultural, es decir teniendo en cuenta cabalmente las fuentes jurídicas romanas, el concepto ciceroniano de Estado además de toda la tradición judaica del pacto entre el pueblo y el rey comentada por S. Agustín-que Salamone propuso la teoría del contrato social por primera vez en una forma ya completa, dispuesta para entrar en el mundo moderno: "Salamonius is a writer of the first importance in the history of the social contract, as important in the history of the social contract proper as Menegold of Lauthenbach is in the history of the contract of government. A number of previsions author, as we have seen, were feeling their way towards the theory, but in Salamonius for the first time we find it stated with the utmost clarity and precision. Details of the content of the pact yet to be filled in, but in essence the doctrine was now fully fledged, and ready to enter the modern world"16. Últimamente, otro importante historiador de la filosofía política moderna, Quentin Skinner, ha sostenido que la aportación fundamental de Salamone -que por cierto considera como uno de los más destacados jurisconsultos del Renacimiento, famoso comentador del Digesto y pionero del humanismo jurídico- fue la interpretación constitucionalista de la antigua Lex Regia romana: "Un destacado jurisconsulto que se valió de estas técnicas humanísticas para fijar una teoría esencialmente bartolista de la soberanía popular fue Andrea Alciato, a quien ya hemos encontrado como primer sabio en exportar los nuevos métodos del humanismo jurídico, de Italia a Francia. Pero el ejemplo más claro de este enfoque sincrético puede encontrarse en la serie de diálogos intitulados La

${ }^{15} \mathrm{~J} . \mathrm{W}$. ALLEN, A history of political thought in the sixteenth century, London, Methuen, 1951, 331-336.

${ }^{16} \mathrm{~J}$. W. GOUGH, The social contract. A critical study of its development, Oxford, Clarendon, 1957, 45. 
soberanía del Patriciado Romano, que Mario Salamone completó en 1514"17. Sin embargo, el mayor estudioso e intérprete contemporáneo de Mario Salamone es, sin duda, el profesor italiano Mario D'Addio ${ }^{18}$ que, en torno al 1950, sacó a la luz por primiera vez los códices latinos del Principado llevando a cabo un trabajo de investigación e interpretación importantisimo.

\section{El Contractualismo de Francisco Suárez}

Como hemos visto, la nueva doctrina política del contractualismo, propuesta por Mario Salamone, representó sin duda una de las perspectivas más notable de la especulación europea del siglo XVI. Con él, tanto el contractualismo como la teoría del tiranicidio, precedió en sesenta años al debate entre los monarcómacos, sean protestantes o católicos, que harían proceder el poder político del pueblo y que defenderán el derecho de resistencia al monarca en determinadas circunstancias. Estas teorías monarcómacas -es decir democráticas y tiranicidas- fueron desarrolladas por los calvinistas italianos, escoceses y franceses a partir de la Declaración de Magdeburgo en Alemania (1550), con el fin de establecer un nuevo poder político en el norte de Europa capaz de detener la hegemonía española de Felipe II en el viejo Continente. Es el caso del italiano Pier Martire Vermigli, de los escoceses John Knox y George Buchanan (De iure Regni apud Scotos), y de los franceses Theodore Beza (De iure magistratuum in subditos et officio subditorum erga magistratus) y Felipe Du Plessis-Mornay, quién escribió la obra más conocida de la época: Vindiciae contra tyrannos publicada en Francia, pocos años después de la Noche de San Bartolomé de 1572. A partir de allí, hubo varios escritores hugonotes y católicos, como Juan Bodino (Los seis libros de la República), Fernando Vázquez (Controversias fundamentales y otras de más frecuente uso), Juan de Mariana (De rege et regis institutione), Johannes Althusius (Politica methodice digesta) y Francisco Suárez (Tractatus de legibus), que siguieron analizando las cuestiones de poner límites al absolutismo monárquico y el derecho de resistencia.

Sin embargo -y volviendo a la época exacta en que Salamone escribió El Principado- al principio del siglo XVI en Europa se impuso otra concepción política que, a pesar de brotar de las experiencias religiosas, culturales y políticas vinculadas con el movimiento europeo de la

\footnotetext{
17 Q. SKINNER, Los fundamentos del pensamiento politico moderno, México, Fondo de Cultura Económica, 1993, Vol. II, 148-152.

18 M. D’ADDIO, Storia delle dottrine politiche, Genova, ECIG, 2002.
} 
Reforma protestante de Martín Lutero, acabó identificándose paradójicamente con el pensamiento político de Maquiavelo. La Reforma protestante, en efecto, había planteado en términos dramáticos el problema de la relación entre la religión y la política. El principio fundamental sobre el que se había organizado la sociedad europea -el ideal de la República Cristiana- fue rechazado y, por consiguiente, surgieron una serie de conflictos que tenían como objetivo por parte católica la restauración de la antigua unidad de la fe y, por parte protestante, la instauración de las nuevas iglesias cristianas. Empezó a cuestionarse si el Estado tenía o no derecho a imponer a sus súbditos el credo religioso oficial; si tenía el derecho a proteger y garantizar las nuevas iglesias cristianas nacidas con la Reforma y sancionar, por tanto, la definitiva desintegración de la unidad de la Iglesia católica; se planteaba, en fin, el problema de si el cristiano tenía o no que obedecer el mandato del Estado que le obligaba a seguir una determinada religión. Naturalmente todos estos problemas volvieron a reconducir el debate sobre el origen del poder político y de la sociedad, y sobre las relaciones entre el poder político y el nuevo mensaje reformado. El resultado fue, sin embargo, que la mayoría de los anabaptistas, luteranos y anglicanos, en lugar de seguir promoviendo una política republicana y democrática, volvieron a considerar al Estado - tal vez por oportunismo político - como la manifestación de la voluntad divina: para todos ellos, en efecto, el poder político procede directamente de Dios o se establece por institución divina. El primero fue Martín Lutero, quien volvió a proponer la típica concepción medieval de la historia como manifestación de la voluntad y justicia de Dios que, por medio de los tiranos, castigaba la maldad y los pecados de los hombres. De tal manera que el promotor de la Reforma - al separar al hombre espiritual del hombre material, el primero libre y el secundo esclavo del pecado - apuntó a un Dios justiciero, llegando incluso a la exaltación de la fuerza cada vez que se hablaba democráticamente de pueblo y de campesinos. Así que la Reforma aceleró paradójicamente la tendencia a aumentar y consolidar el absolutismo monárquico: "Martín Lutero descubrió pronto que el éxito de la Reforma de Alemania dependía de la posibilidad de obtener la ayuda de los príncipes. En Inglaterra, la Reforma la llevó a cabo el poder, ya casi absoluto de Enrique VIII, y su consecuencia inmediata fue robustecer aún más el poder real. En términos generales, puede decirse que, a medida que las controversias se extendían, el rey quedaba en toda Europa como único punto alrededor del cual pudiera realizarse la unidad nacional. Esto es especialmente cierto de Francia en la última parte del siglo XVI. Puede afirmarse sin mucha exageración que en todas partes el éxito correspondió 
al partido religioso que resultaba aliado de los príncipes"19. Con la Reforma protestante, pues, los reyes ganaron y la monarquía absoluta, que no tuvo su origen en la Reforma y que no estaba más relacionada naturalmente con una forma de creencia religiosa que con otra, fue en primera instancia su principal beneficiario político. En este momento nace efectivamente -primero en Francia con el rey Luis XIV y luego en Escocia con el rey de Inglaterra Jacobo Ila teoría del derecho divino de los reyes; quien la expuso fue el mismo Jacobo I, cuya obra True Law of Free Monarchies se publicó en 1598.

Ahora bien, en este difícil contexto cultural y político, la Reforma católica - es decir, el movimiento nacido para llevar a cabo una profunda renovación de la vida de la Iglesia a través del respeto de los principios y valores de la tradición - tuvo el indiscutible mérito de haber vuelto a considerar los temas relativos a la concepción de la comunidad política dentro del ámbito del derecho natural (teoría que había sido desarrollada por Tomás de Aquino y la Escuela Jurídica italiana), para alcanzar una concepción sistemática de los problemas que se refieren al origen al fundamento de la sociedad política y del poder, basada sobre la naturaleza racional y la igualdad y libertad de todos los hombres. Y la orientación doctrinaria que pretendió resolver los problemas de la política a través de los principios del derecho natural reconsiderados a la luz de las fuentes clásicas - fue planteada por los teólogos y jurista españoles del siglo XVI, que contribuyeron significativamente al desarrollo del iusnaturalismo tal como se expresaría luego en la famosa obra De iure belli ac pacis de Hugo Grocio. En efecto, los problemas causados por el imperialismo español de Carlos V, es decir las relaciones que España había que establecer con los pueblos americanos sometidos a la conquista, la manera de entender la posición de España en el conjunto del mundo, la relación entre la comunidad política y el poder político, entre el Estado y la Iglesia, constituyeron los temas más interesantes de estos autores: en efecto, las obras de Francisco de Vitoria (De Potestate Civili), Domingo de Soto, Fernando Vázquez, Juan de Mariana y, sobre todo, Francisco Suárez (Defensio Fidę) representan las fuentes más significativas de la nueva concepción del derecho natural que habrá de informar el pensamiento político europeo entre la mitad del siglo XVI y el XVII. Por lo tanto resulta lógico que todos los autores de la Escuela de Salamanca tomaran en debida consideración la tradición política grecorromana y judaicocristiana sistematizada por la Escuela jurídica italiana y, sobre todo, por su máximo exponente

${ }^{19}$ G. H. SABINE, Historia de la teoría política, México, Fondo de Cultura Económica, 2002. 
Mario Salamone. Y en efecto tanto los autores de la Escuela de Salamanca, como el gran jurista y máximo representante del movimiento calvinista alemán del siglo XVII, Johannes Althusius, profundizaron los cuatros pilares de la doctrina del contractualismo de Mario Salamone (los conceptos de soberanía popular, pacto social, pacto de gobierno y derecho de resistencia) y, máxime, utilizaron el argumento de la Lex Regia como prueba histórica para demostrar el fundamento ético-jurídico y los límites del poder político. En sus obras políticas: el Tratado de las leyes y de Dios legislador (1613) y la Defensio fidei III. Principatus politicus o la soberania popular (1613), por ejemplo, Suárez intentó dar respuesta a todos los problemas causados por la Reforma protestante que -con los anabaptistas, luteranos y anglicanos- había vuelto a considerar el Estado como una manifestación de la voluntad divina: para todos ellos, en efecto, el poder político de los reyes procede directamente de Dios o se establece por institución divina. Por el contrario el teólogo granadino, inspirándose a la concepción tomista del derecho natural, rechazó no solamente la idea luterana del Estado como «espada de Dios», sino también la nueva teocracia anglicana y defendió rotundamente la autonomía del poder político, afirmando la distinción tradicional entre lo temporal y lo espiritual. Así como el Estado no está sometido a la Iglesia, de la misma manera la Iglesia no puede entrometerse en los asuntos del Estado: según el autor, pues, el derecho natural constituye no solamente el fundamento del Estado, sino también el presupuesto ineludible para la constitución de un gobierno civil. Suárez rechazó rotundamente el absolutismo monárquico que se basaba en el derecho divino de los reyes, tal como había sido propuesto por el rey de Inglaterra Jacobo I: para el teólogo granadino esta opinión no encuentra confirmación alguna en el derecho natural puesto que, desde el punto de vista político, el rey es responsable ante la comunidad. Toda la Defensio fidei, por tanto, tiene el objetivo de cuestionar razonablemente la opinión anglicana por la cual el poder proviene directamente de Dios, o (lo que es lo mismo), que Dios es la causa inmediata y el autor del poder político.

Suárez, en efecto, al retomar la concepción tomista de la comunidad política, define la comunidad como un cuerpo político constituido por los individuos: pero la summa potestas no procede de los individuos (el hombre no puede dominar y constreñir a sus semejantes porque es originariamente libre y tiene el derecho de autogobernarse), sino de la comunidad. Efectivamente la esencia del poder político reside en el mando, es decir en la posibilidad de imponer a todos los asociados un determinado comportamiento -también con el uso de la fuerza- y es por eso por lo que los individuos encomendaron o delegaron la summa potestas a 
los gobernantes: "Por consiguiente hay que decir que este poder, por la sola naturaleza de la cosa, no reside en ningún hombre particular sino en el conjunto de los hombres. Esta tesis es general y cierta. Se encuentra en Santo Tomás, el cual piensa que el soberano tiene el poder para promulgar las leyes y que ese poder se lo trasfirió a él la comunidad, como lo traen también y lo confiesan también las leyes civiles. Lo enseñan también Castro, Soto, Ledesma, Covarrubias y Azpilicueta. La razón de la primera parte es evidente y la indicamos al principio, y es que por naturaleza todos los hombres nacen libres y por eso ninguno tiene jurisdicción política sobre otro - como tampoco tiene dominio - ni hay ninguna razón para que esto, dada la naturaleza de la cosa, se conceda a éstos respecto de aquellos más bien que al revés"20. Para explicar más claramente el origen del poder político, Suárez criticó la interpretación de lo político basada en el supuesto derecho paternal absolutista, tal como había hecho ya Salamone en El Principado, sosteniendo que la potestad política del padre/Príncipe es inferior a la de la familia/Estado en su conjunto, porque es inaceptable que una parte sea superior a la totalidad. Suárez profundizó ese concepto al afirmar que el poder del pater familiae no es superior al de su mujer o de sus hijos puesto que hay que distinguir entre la potestas economica (el poder de dirección y guía) y la potestas iurisdictionis (el poder político de mando, imposición y coacción). Adán, explica el autor, no tuvo la potestas iurisdictionis sino la potestas economica, y así todos los padres de familia: el poder político se constituyó sólo posteriormente y por voluntad de las familias que -para encarar sus necesidades- formaron una comunidad más amplia: "Únicamente podría decir alguno que Adán, al principio de la creación, tuvo naturalmente el primado y consiguientemente el imperio sobre los hombres y que así pudo derivarse de él o por el origen natural de los primogénitos o según la voluntad del mismo Adán. (...) Pero, en fuerza de la sola creación y del origen natural, sólo puede deducirse que Adán tuvo el poder económico, no el político, porque tuvo poder sobre su esposa y después el poder paterno sobre sus hijos mientras no se emanciparon; pudo también con el tiempo tener criados y una familia completa y en ella pleno poder, que se llama poder económico. Pero una vez que comenzaron a multiplicarse las familias y a separarse uno a uno los hombres para ser cabezas de cada una de las familias, tenían ellos ese mismo poder sobre su propia familia. El poder político no comenzó hasta que varias familias comenzaron a reunirse en una sociedad

\footnotetext{
${ }^{20}$ F. SUÁREZ, Tratado de las Leyes y de Dios Legislador, 201-202.
} 
perfecta"21. El poder político o potestas iurisdictionis, por tanto, descansa en la comunidad política y constituye el principio de su independencia, autonomía y libertad; y, por eso, la comunidad política tiene el derecho de mandar sobre los individuos asociados. Además, según Suárez, no se puede entender la comunidad política como un conglomerado de individuos sin ningún orden ni vínculo físico y moral; al contrario, hay que considerar la multitud humana "bajo otro aspecto, en cuanto que, por un deseo especial o consentimiento general, se reúnen en un cuerpo político con un vinculo de sociedad y para ayudarse mutuamente en orden a un fin político, de la misma manera que forman un cuerpo místico que moralmente puede llamarse uno por su naturaleza"22.

La consecuencia más importante del hecho de que el poder o la potestas iurisdictionis procede del cuerpo político, es que los reyes no obtienen la soberanía directamente de Dios como sostenían los anglicanos partidarios del derecho divino de los reyes- sino de la misma sociedad. Eso quiere decir que el rey tiene que responder de su conducta moral no solamente ante Dios, sino también ante la comunidad; por consiguiente, afirma Suárez, el pueblo tiene el derecho a la oposición y deposición del monarca, incluso a su condena a muerte. La legitimación del derecho de resistencia contra el tirano se fundamenta, pues, en el hecho de que la forma de gobierno o constitución política - sea esa monárquica, aristocrática o democrática- se basa sobre el derecho civil de la sociedad. Por eso, no hay que extrañarse si la Defensio fidei fue condenada en Francia, aliándose para ello la Sorbona y el Parlamento de París. La condena se reitera con virulencia por los Estados Generales de 1615, reafirmándose en la opinión de que es impía la opinión que considera justo matar a los reyes, sea cuales fueren las circunstancias, puesto que el soberano sólo debe rendir cuentas a Dios. Jacobo I, manda quemar la Defensio fidei en un acto público en Londres, prohíbe su lectura en Inglaterra y arremete contra la Compañía de Jesús en el prólogo a la traducción inglesa de las condenas de París"23. En efecto, en el tercer libro de la obra Defensio fidei, titulado Principatus politicus o la soberania popular, Suárez afirma rotunda y finalmente que ningún rey o monarca recibe o ha recibido nunca el poder político directamente de Dios (o por derecho divino), sino más bien mediante un "pacto voluntario» de la sociedad civil. Y para aclarar el fundamento político de ese pacto social - es decir la soberanía popular- utiliza el argumento de la Lex Regia expuesto

\footnotetext{
${ }^{21}$ F. SUÁREZ, Tratado de las Leyes y de Dios Legislador, 202.

${ }^{22}$ F. SUÁREZ, Tratado de las Leyes y de Dios Legislador, 202.

${ }_{23}$ M. MACEIRAS FAFIÁN, Pensamiento filosófico español, Madrid, Síntesis, 2002, Volumen I, 330-331.
} 
en El Principado de Salamone. Para Suárez, en efecto, el acto de concesión del poder por parte de la comunidad tiene que ser considerado como un verdadero pacto mediante el cual el poder es otorgado al monarca bajo determinadas condiciones que tienen que ser respetadas por el soberano; en caso contrario, el pueblo puede legítimamente destituir al monarca. En ese sentido hay que entender no solamente la afirmación sobre el pacto social de San Agustín, sino sobre todo la famosísima Lex Regia del Digesto: "La opinión de San Agustín confirma magistralmente esta tesis cuando dice 'Pacto general de la sociedad humana es obedecer a sus reyes'. Con estas palabras significa que el poder de los reyes y la obediencia que se les debe, tiene su fundamento en un pacto de la sociedad humana, $y$, por consiguiente, que no tiene su origen en la inmediata institución divina, pues el pacto humano se contrae por voluntad de los hombres. Quizás se expresa este pacto en el Digesto con el nombre de ley regia, cuando dice Ulpiano que por eso el deseo del príncipe tiene fuerza de ley, porque mediante la ley regia que se dio sobre su poder, el pueblo le transfirió toda su potestad y autoridad sobre él. Aceptó y transcribió estas palabras el emperador Justiniano en las Instituciones. Y no se llama regia aquella ley porque haya sido dada por un rey, sino porque se ha dado sobre el poder del rey, como se dice en la misma ley. Se indica también allí que el rey ha sido constituido por el pueblo al crear e instituir la dignidad real trasladando a él su poder, como la glosa y los doctores comentan. Ahora bien, no pudo darse aquella ley a la manera de un sólo precepto, porque haya abdicado el pueblo mediante ella del supremo poder de hacer justicia. Debe entenderse, pues, que ha sido constituida por medio de un pacto con el cual el pueblo trasladó al príncipe el poder con la carga y obligación de gobernar al pueblo y administrar justicia; y el príncipe aceptó tanto el poder como la condición. Por razón de este pacto permaneció firme y estable la ley regia o el poder del rey. En consecuencia, no recibieron los reyes este poder directamente de Dios, sino del pueblo. Por eso se dice en el Digesto: Al no poder el Senado gobernar bien todas las provincias, después de nombrar un rey se dio derecho de ratificar lo que hubiese legislado"24.

En conclusión, para Suárez las normas jurídicas, fundadas en el derecho natural, regulan la existencia de la sociedad política: por consiguiente no hay que entender el poder político en términos absolutistas o sagrados, puesto que quien detenta el poder no puede

\footnotetext{
24 F. SUÁREZ, Defensio fidei III. Principatus politicus o la soberanía popular, Madrid, Consejo Superior de Investigaciones Científicas, 1965, Cap. II, 26.
} 
atribuirse ninguna investidura divina ni tampoco sustraerse al control de la comunidad. Al manifestarse dentro del ámbito de las leyes civiles, el poder político queda así «constitucionalizado», gozando sus normas de un valor superior a la voluntad de quien detenta el poder: el derecho natural se convierte así en la fuente del derecho positivo, sobre la base del cual tiene que gobernarse la comunidad política. De tal manera que para Suárez -al igual que para Salamone- no sólo la soberanía popular constituye el fundamento ético del Estado, es decir la esencia de lo político, sino que también el poder político encuentra sus límites en los derechos naturales y positivos. 